\section{REVIEW ARTICLE}

\title{
Options for the control of enterohaemorrhagic Escherichia coli in ruminants
}

\author{
Mark P. Stevens, Pauline M. van Diemen, Francis Dziva, Philip W. Jones \\ and Timothy S. Wallis
}

Author for correspondence: Mark P. Stevens. Tel: +44 1635578411. Fax: + 441635577243.
e-mail: mark-p.stevens@bbrc.ac.uk

Division of Environmental Microbiology, Institute for Animal Health, Compton Laboratory, Compton, Newbury RG20 7NN, UK

Keywords: Escherichia coli, Shiga toxin, colonization, bovine, infection

\section{Overview}

Enterohaemorrhagic Escherichia coli (EHEC) comprise an important group of zoonotic enteric pathogens. In humans, some EHEC infections result in bloody or nonbloody diarrhoea, which may be complicated by haemorrhagic colitis and severe renal and neurological sequelae, including haemolytic uraemic syndrome (HUS). Ruminants are an important reservoir of EHEC and human infections are frequently associated with direct or indirect contact with ruminant faeces. Strategies to reduce the prevalence of EHEC in ruminants should lower the incidence of human infection. However, little is currently known about the mechanisms of intestinal colonization of ruminants by EHEC and no effective vaccines have yet been developed. Here we review current knowledge on the host responses to EHEC infection and the factors mediating EHECintestinal interactions and survival in cattle and sheep. Perspectives for the use of vaccines, probiotics and other measures to control EHEC in farm animals are discussed.

\section{Epidemiology of EHEC}

EHEC are an emerging group of enteric pathogens of animals and humans (Nataro \& Kaper, 1998). Human infections caused by EHEC have been reported with increasing frequency over the past 15 years in many countries and may involve severe enterocolitis and systemic sequelae (Slutsker et al., 1997; Anon, 1998; Paton \& Paton, 1998). The leading antecedent to EHEC infection is direct or indirect contact with ruminant faeces (Locking et al., 2001; O'Brien et al., 2001). Outbreaks are commonly attributed to the consumption of contaminated meat, milk and dairy products, in particular those derived from cattle (Griffin, 1995 ; Armstrong et al., 1996); however, outbreaks have also resulted from the consumption of water, unpasteurized apple drinks and vegetables contaminated with ruminant faeces (Olson et al., 2002; Cody et al., 1999; Hilborn et al., 1999). Direct contact with ruminant faeces on farms and on contaminated pastures has also resulted in outbreaks of EHEC infection (O'Brien et al., 2001; Ogden et al., 2002). Farm animals are widely regarded to be the principal reservoir of EHEC, but the bacteria have been detected in a growing number of wild animals and birds (Mainil, 1999). Wild and domestic animals may act as vectors for transmission of EHEC to farm animal hosts and on rare occasions humans. Indeed rabbits were recently implicated in an outbreak of EHEC infection in visitors to a wildlife centre in Great Britain (Pritchard et al., 2001).

The O-serotype predominantly associated with human infections in Great Britain is O157 and isolations have almost doubled in the last 6 years (Anon, 2000). Other EHEC serotypes (particularly O26, O111, O128 and O103) are emerging as a common cause of human disease in many countries and indeed may be more prominent than O157 (Bettelheim, 2000). It is presently unclear if the incidence of human infections caused by these serotypes correlates with the prevalence of the bacteria in farm animal hosts. In a recent survey of nonO157 Shiga-toxin-producing E. coli isolates from Scottish cattle, 8 of the 11 different $O$-serogroups represented have also been associated with bloody diarrhoea in humans and HUS (Jenkins et al., 2002). Interestingly, O26 and O111 EHEC were not isolated in this study, although they have been isolated from healthy cattle in other studies (Kobayashi et al., 2001). It remains unclear if all EHEC present in animal reservoirs present a risk to the human population. Further, it is not known why some EHEC serotypes (e.g. O157) can cause disease in humans but not in cattle. EHEC isolated from healthy cattle often possess the same combinations of putative virulence genes that are found in human isolates (Wieler et al., 1996; Sandhu et al., 1996; Kobayashi et al., 2001; Jenkins et al., 2002). However, differences in expression of these genes have been detected among human and bovine isolates in vitro and this may affect 
the potential for zoonotic transmission (McNally et al., 2001).

In a recent 12-month survey of cattle and sheep presented for slaughter at abattoirs in Great Britain, $4.7 \%$ of cattle and $1.7 \%$ of sheep contained E. coli $\mathrm{O} 157$ in the faeces (Paiba et al., 2002). Further, it was reported that up to $44 \%$ of cattle herds in Great Britain have at least one animal shedding E. coli $\mathrm{O} 157$ (Paiba et al., 2002). The E. coli $\mathrm{O} 157$ phage types most frequently isolated from cattle (2, 8 and 21/28) and sheep (4 and 32) were the same five types predominantly associated with illness in humans in Great Britain during the same period (Paiba et al., 2002). The incidence of EHEC serotypes other than O157 that may pose a risk to humans was not determined in this study. In the United States, the prevalence data are even higher, with an estimated $28 \%$ of beef cattle shedding E. coli $\mathrm{O} 157: \mathrm{H} 7$ in the summer months (Gansheroff \& O'Brien, 2000; Elder et al., 2000).

The prevalence of EHEC is higher in younger animals and in animals subject to transit, feed changes and antimicrobial therapy, possibly due to disturbance in the resident intestinal microflora (Hancock et al., 1998). The shedding patterns are characterized by sharp bursts of EHEC excretion in a high percentage of animals separated by longer periods of very low prevalence. E. coli $\mathrm{O} 157: \mathrm{H} 7$ is capable of efficient transmission between animals, even at very low doses (Besser et al., 2001). To add to the problem, animals colonized by EHEC are hard to identify since E. coli O157:H7 infections in weaned calves and adult cattle and sheep are asymptomatic (Cray \& Moon, 1995; Brown et al., 1997; Dean-Nystrom et al., 1998a, 1999; Cornick et al., 2000; Wray et al., 2000). The infectious dose for E. coli O157: H7 in humans has been estimated to be less than 100 c.f.u. (Griffin, 1995). Calves and adult cattle experimentally infected with EHEC can excrete large numbers of EHEC for up to several weeks depending on the inoculation dose (Cray \& Moon, 1995 ; Brown et al., 1997; Sanderson et al., 1999; Cornick et al., 2000; Wray et al., 2000). The magnitude and duration of excretion of EHEC by naturally infected animals is less well studied, therefore the risk to human health posed by ruminants colonized by EHEC is difficult to quantify. Some EHEC serotypes (e.g. O5, O26 and O118) are associated with enteric disease in farm animals and cause significant morbidity and mortality (Mainil, 1999; Bettelheim, 2000).

\section{Host responses to EHEC infection}

Infection of the gastrointestinal tract of adult cattle, weaned calves and 5-day-old gnotobiotic calves by EHEC serotype O157:H7 is asymptomatic (Cray \& Moon, 1995; Brown et al., 1997; Dean-Nystrom et al., 1999; Sanderson et al., 1999; Woodward et al., 1999; Wray et al., 2000). Histological analysis of intestinal epithelia from calves and cattle infected with E. coli $\mathrm{O} 157: \mathrm{H} 7$ reveals intimate bacterial adherence in some but not all cases and a mild inflammatory response characterized by diffuse infiltration of neutrophils into the lamina propria. Infection of neonatal colostrumdeprived calves with E. coli $\mathrm{O} 157: \mathrm{H} 7$ results in diarrhoea and colonic oedema (Dean-Nystrom et al., 1997); however, such animals are atypically susceptible to infection. E. coli $\mathrm{O} 157: \mathrm{H} 7$ also persistently colonizes the intestines of neonatal lambs and sheep in the absence of clinical signs (Kudva et al., 1995, 1997; Cornick et al., 2000; Wales et al., 2001a, b).

Natural and experimental infection of susceptible calves with bovine virulent EHEC serotypes frequently produces diarrhoea, villous atrophy, epithelial cell damage, infiltration of neutrophils into the lamina propria and intestinal lumen and the formation of a pseudomembrane containing blood, fibrin, cellular debris and neutrophils (Hall et al., 1985; Chanter et al., 1986; Pearson et al., 1999; Mainil, 1999). Similar histopathological lesions occur in some cases of EHECassociated haemorrhagic colitis in humans (Slutsker et al., 1997).

Distal sites in the intestine such as the caecum, colon and rectum are believed to be the principal sites of E. coli O157: H7 colonization in ruminants (Cray \& Moon, 1995; Brown et al., 1997; Dean-Nystrom et al., 1998a, 1999; Wales et al., 2001a, b; Grauke et al., 2002). We and others have observed little, if any, direct interaction between E. coli O157:H7 and the epithelium of the lower gastrointestinal tract in experimentally infected conventional calves (M. Stevens, unpublished observations; Wray et al., 2000). In contrast, extensive bacterial adherence to the colonic epithelium is seen in calves infected with EHEC serotype O5 (Hall et al., 1985; Chanter et al., 1986), O26 (Pearson et al., 1999) and O111 (Stevens et al., 2002b). Similar observations have been made in bovine ileal and colonic loops infected with O157 and non-O157 strains (Sandhu \& Gyles, 2002). Thus E. coli O157 and non-O157 serotypes may use distinct mechanisms to colonize the ruminant host. Differences in tissue tropism may have implications for the control of EHEC colonization in cattle and raise important questions about the likely efficacy of mucosal immune responses against bacteria existing in different intestinal niches.

Serum antibody responses against the O157 lipopolysaccharide and Shiga toxin 1 have been detected in some but not all experimentally infected calves (Johnson et al., 1996; Wray et al., 2000) and sheep (Cornick et al., 2000). Neutralizing antibody responses against Stx2 were not detected following E. coli O157:H7 infection of calves (Johnson et al., 1996). Anti-LPS and Stx1 responses in calves could not be correlated with the elimination of E. coli $\mathrm{O} 157: \mathrm{H} 7$ and failed to reduce faecal shedding of the bacteria following re-inoculation with the same strain (Johnson et al., 1996; Wray et al., 2000). In contrast, Sanderson et al. (1999) reported that calves re-infected with E. coli O157:H7 shed the organism for a shorter duration following the second or third inoculation. Diarrhoeic calves experimentally infected with an O5 calf dysentery EHEC strain did not present with dysentery following a second challenge 
(Chanter et al., 1986). However, susceptibility of calves to this strain is age-related (Chanter et al., 1986), therefore the lack of symptoms following re-inoculation may not necessarily be the result of acquired immunity. Further studies are required to measure the induction and efficacy of humoral and cell-mediated immune responses to EHEC following natural and experimental infection of ruminants.

The induction of intestinal secretory and inflammatory responses to different EHEC serotypes and defined bacterial mutants has been quantified in bovine ligated intestinal loop models (Stevens et al., 2002a; Sandhu \& Gyles, 2002). Whilst O157 strains were not strongly enteropathogenic, fluid accumulation and a pronounced infiltration of neutrophils was seen in response to EHEC serotypes O103 (Stevens et al., 2002a) and O5, O26 and O111 (Sandhu \& Gyles, 2002). This provides a valuable model to dissect the role of bacterial factors in EHECinduced enteritis and intestinal colonization.

\section{Factors mediating colonization of the bovine intestine by EHEC}

EHEC are closely related to enteropathogenic E. coli (EPEC), which are a leading cause of infantile diarrhoea in developing countries, and share many of the EPEC genes implicated in virulence (Frankel et al., 1998; Roe \& Gally, 2000). EHEC induce a characteristic histopathology on intestinal epithelia known as the 'attaching and effacing' (AE) lesion (Nataro \& Kaper, 1998). The bacteria adhere intimately to the apical surface of enterocytes on actin-rich pedestals and microvilli in the brush border are destroyed (Fig. 1). The genes that determine the AE phenotype have been mapped to a chromosomal pathogenicity island known as the locus for enterocyte effacement (LEE). The LEE encodes a type III protein secretion system that delivers a set of bacterial proteins into the host cell cytoplasm or apical membrane (Frankel et al., 1998). In EPEC and EHEC, several proteins are exported by the type III secretion system, some of which subvert pathways that regulate the host cell cytoskeleton and bring about pedestal formation (Frankel et al., 1998). One of the translocated proteins (Tir) becomes inserted in the apical membrane of enterocytes, where it acts as a receptor for a bacterial outer-membrane protein called intimin (Eae) (DeVinney et al., 1999). Intimin can also bind to $\beta 1$-integrins (Frankel et al., 1996) and to cell-surface localized nucleolin (Sinclair \& O’Brien, 2002); however, the significance of this in intestinal colonization is not known.

The cell-binding activity of intimin has been localized to the carboxy-terminal 280 amino acids (Int280) of the polypeptide (Frankel et al., 1994). Recently, several distinct Int280 subtypes, designated intimin $\alpha, \beta, \gamma, \delta, \varepsilon$ and $\theta$, have been identified which were specifically associated with distinct EPEC and EHEC serotypes (Adu-Bobie et al., 1998). A further group of strains of different serotypes exists for which the intimin type was non-typable (NT). Different intimin subtypes confer a tropism for different intestinal sites (Phillips \& Frankel, 2000). Intimin $-\gamma$ (expressed by EHEC O157: H7) confers a specificity for follicle-associated epithelium overlying Peyer's patches in the human distal ileum (Phillips \& Frankel, 2000). Expression of intimin- $\alpha$ (expressed by EPEC) in E. coli $\mathrm{O} 157: \mathrm{H} 7$ results in infection spreading to small intestinal mucosal surfaces (Fitzhenry et al., 2002). Similar observations have been made in a
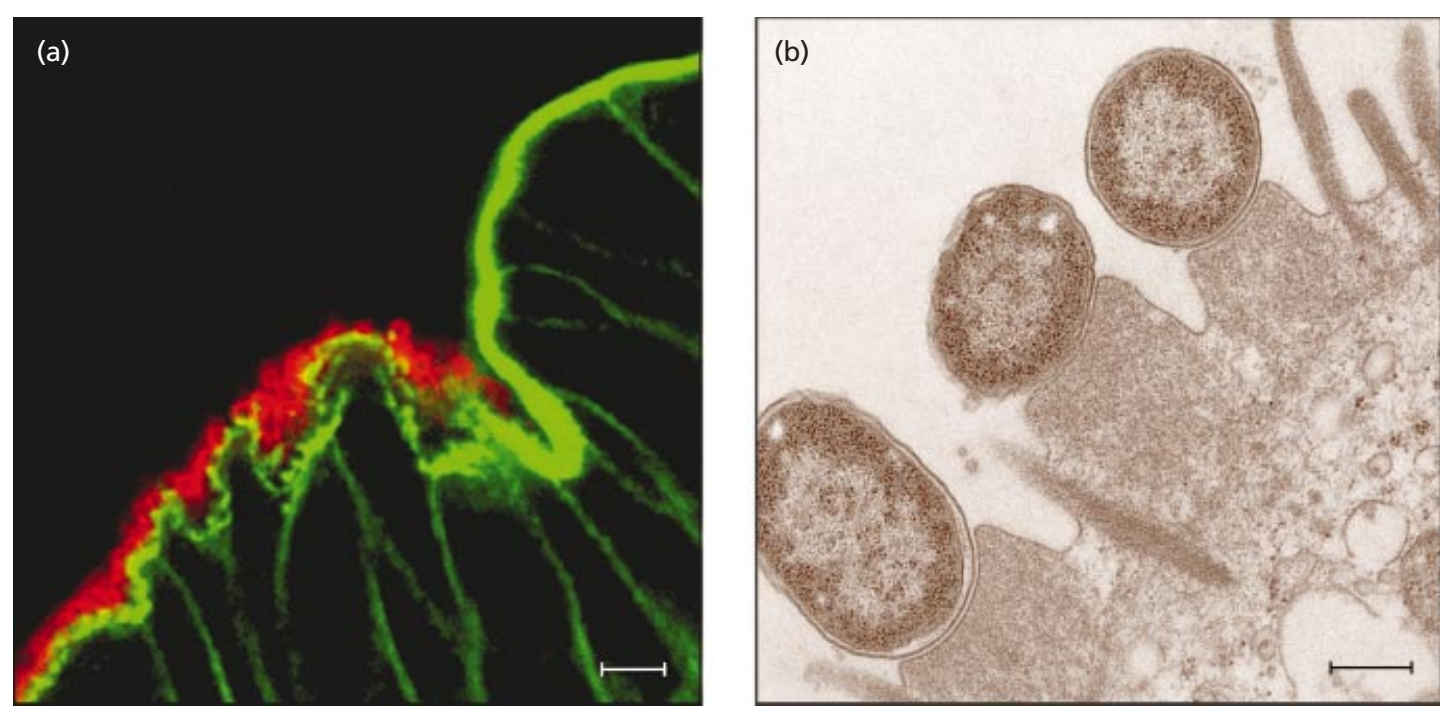

Fig. 1. (a) Confocal laser scanning micrograph showing extensive adherence of an $0111: \mathrm{H}^{-}$EHEC strain to the epithelium of the bovine spiral colon. The tissue was analysed 3 days after oral inoculation of an 11-day-old conventional Friesian bull calf with $10^{10}$ c.f.u. of EHEC strain E45035N (Stevens et al., 2002b). Bacteria are stained red with a fluorophoreconjugated antibody against the LPS and F-actin in the mucosa is stained green with fluorophore-conjugated phalloidin (bar, $10 \mu \mathrm{m}$ ). (b) Transmission electron micrograph of the same tissue showing attaching and effacing (AE) lesions induced by the bacteria on colonic enterocytes (bar, $1 \mu \mathrm{m})$. 
gnotobiotic piglet model (Tzipori et al., 1995). It is presently unclear if intimin-mediated tissue tropism correlates with the ability of some EHEC serotypes to successfully colonize both human and ruminant hosts.

Intimin has been shown to play a key role in intestinal colonization in colostrum-deprived neonatal calves and piglets by E. coli $\mathrm{O} 157: \mathrm{H} 7$ and in the induction of colonic oedema and diarrhoea (Donnenberg et al., 1993; McKee et al., 1995; Tzipori et al., 1995; DeanNystrom et al., 1998b). Intimin also influences colonization of adult cattle and sheep (Cornick et al., 2002). However, the eae gene is not present in all Shiga-toxinproducing E. coli strains isolated from diarrhoeic calves and healthy cattle (Wieler et al., 1996; Sandhu et al., 1996; Jenkins et al., 2002), indicating that other factors influencing persistence of the bacteria in the bovine intestine may be important. The finding that eae null mutants still colonize some compartments of the intestinal tract of calves and sheep (Dean-Nystrom et al., 1998b; Cornick et al., 2002) supports the notion that accessory adhesins and/or growth in the lumenal contents may influence carriage. A number of loci have been implicated in the attachment of EHEC to epithelial cells in vitro, including LEE-encoded EspA filaments (Ebel et al., 1998), Iha (Tarr et al., 2000) and several other genes identified by transposon mutagenesis of $E$. coli $\mathrm{O} 157$ : H7 (Tatsuno et al., 2000). To our knowledge, the role of these genes in colonization of the ruminant intestine has not yet been tested.

LEE-negative Shiga-toxin-producing E. coli strains have also been implicated in outbreaks of human disease and HUS (Paton et al., 1999). Recently, two factors encoded on the large plasmid of an O113:H21 LEE-negative isolate implicated in an outbreak of HUS were found to mediate attachment of the bacteria to cultured epithelial cells. One is an autoagglutinating adhesin (Saa) (Paton et al., 2001) and the other is a novel type IV pilus (Srimanote et al., 2002). The distribution of the saa and pil loci among LEE-negative EHEC strains isolated from ruminants and their role in intestinal colonization remains to be studied.

Recently, we have identified a gene (efa1) that mediates colonization of the bovine intestine by non-O157 EHEC (Stevens et al., 2002b). Efa1 (EHEC factor for adherence) was recently implicated in adherence of a clinical O111: $\mathrm{H}^{-}$EHEC strain to cultured Chinese Hamster Ovary cells (Nicholls et al., 2000). Mutation of the efa1 gene of EHEC serotypes O5 and O111 significantly reduced faecal shedding and bacterial adherence to the colonic epithelium in experimentally infected calves (Stevens et al., 2002b). EHEC strains harbouring the efa1 mutation were found to express and secrete slightly less of the LEE-encoded effector proteins (Stevens et al., 2002b).

The $e f a 1$ gene is present in all non-O157 strains so far tested (Nicholls et al., 2000; Klapproth et al., 2000), and is identical in size and $99.9 \%$ identical in nucleotide sequence to a gene in EPEC (lifA) encoding a lymphocyte inhibitory factor (lymphostatin). Lymphostatin confers the ability to inhibit the proliferation of human peripheral blood lymphocytes and the mitogen-stimulated synthesis of interleukin-2, -4, -5, and interferon- $\gamma$ (Klapproth et al., 2000). The predicted product of lif A also inhibits the proliferation of human and murine gastrointestinal lymphocytes, indicating that it may modulate mucosal immunity in the gut (Malstrom \& James, 1995; Klapproth et al., 1996). EHEC strains can inhibit the proliferation of bovine peripheral blood monocytes, however it is not yet clear if this activity is attributed to the efa1 gene (Stevens et al., 2002b). Thus Efa1 may influence colonization of the bovine intestine in several ways. It may act as an adhesin per se, it may promote EHEC survival in the bovine gut by modulating mucosal immunity, or it may act indirectly by influencing the expression and secretion of LEE-encoded proteins or other membrane-associated proteins that influence colonization.

Whilst E. coli O157: H7 lacks the full-length $e f a 1$ gene, analysis of the genome sequence has revealed that a truncated version of the efa1 gene encoding the $\mathrm{N}$ terminal 433 amino acids of the protein exists in the chromosome (Stevens et al., 2002b). A transposon insertion upstream of the truncated $e f a 1$ gene was recently shown to reduce bacterial adherence to human colon carcinoma cells (Tatsuno et al., 2000). E. coli O157:H7 strains also encode a homologue of efa1 (toxB/l7095) on the pO157 virulence plasmid (Nicholls et al., 2000). E. coli O157:H7 strains containing derivatives of $\mathrm{pO} 157$ that lack toxB exhibit reduced adherence to cultured epithelial cells, possibly owing to a reduction in the production and secretion of LEEencoded type III secreted proteins (Tatsuno et al., 2001). The to $x B$ gene has also been suggested to be a functional homologue of lymphostatin, since an E. coli O157:H7 strain cured of pO157 lacked the ability to inhibit IL-2 and IL-4 synthesis in mitogen-activated human PBMCs (Klapproth et al., 2000). Thus the E. coli O157:H7 truncated $e f a 1$ and toxB genes may influence intestinal colonization in ruminants in a similar manner to efa 1 in non-O157 EHEC.

The role of Shiga toxins in EHEC intestinal colonization and enteropathogenesis in ruminants is unclear. Nearly all E. coli O157 strains isolated from animals at slaughter in Great Britain contain the stx 2 gene $(97 \cdot 8 \%$ of cattle isolates and $100 \%$ of sheep isolates), and 19.9 and $1.4 \%$, respectively, contained both stx 1 and stx 2 genes (Paiba et al., 2002). This suggests a strong correlation between possession of stx genes and colonization of the ruminant host. Receptors for Stx have been detected on bovine intestinal crypt cells (Hoey et al., 2002), and it has been reported that purified Stx1 can inhibit the activation and proliferation of bovine lymphocytes (Menge et al., 1999; Ferens \& Hovde, 2000). Thus Stx may facilitate intestinal colonization by modulating the mucosal immune response. Dean-Nystrom et al. (1998a) reported that an Stx-producing E. coli O157:H7 strain colonized weaned calves better than a non-producing strain; however, the strains used were not isogenic and differences in colonization may have been due to traits other 
than Stx production. Stx1 does not appear to be involved in the induction of intestinal secretory and inflammatory responses to EHEC serotype O103: $\mathrm{H} 2$ in bovine ligated ileal loops (Stevens et al., 2002a).

The role of flagella, fimbriae and other surface appendages in colonization of the ruminant intestine by EHEC remains to be tested. Flagella and/or motility are important for colonization, invasion and persistence in several enteric pathogens (La Ragione et al., 2000; AllenVercoe et al., 1999). The EPEC H6 flagellin was recently shown to mediate adherence to epithelial cells (Girón et al., 2002); however, $\mathrm{H} 7$ flagella expressed by many $E$. coli $\mathrm{O} 157$ isolates lacked this activity. E. coli $\mathrm{O} 157: \mathrm{H} 7$ encodes 14 different fimbrial operons, however it is presently unclear which if any of these contribute to adherence. Indeed, E. coli O157 contains intact genes for the expression of type I fimbriae, however these are not expressed owing to a deletion in the fimA promoter (Roe et al., 2001).

\section{Insights from comparative and functional genomics in $E$. coli 0157: $\mathrm{H7}$}

The complete genome sequences of two E. coli O157: H7 strains have been determined (Perna et al., 2001; Hayashi et al., 2001). Comparison of the genome sequence of strain EDL933 with that of the K-12 laboratory strain of E. coli has revealed that E. coli $\mathrm{O} 157: \mathrm{H} 7$ contains an extra $1.34 \mathrm{Mb}$ of sequence encoding 1387 O157-specific genes organized mostly in 177 so-called O-islands (Perna et al., 2001). Approximately $60 \%$ of O157-specific predicted genes have no known function. However, it has been possible to identify 14 different genes encoding known or putative non-fimbrial adhesins, a second putative type III protein secretion system similar to the Salmonella Inv/Spa apparatus, a large number of bacteriophage-related sequences and several putative toxins (Perna et al., 2001; Hayashi et al., 2001). This has provided researchers with valuable clues about how E. coli colonizes animal hosts and produces disease. Targeted disruption of candidate virulence genes and the testing of defined mutants in relevant experimental animal models is required to determine the role of these genes in vivo.

Given the size of the E. coli O157:H7 genome (approx. $5.5 \mathrm{Mb}$ ) and the large number of O157-specific genes, we have adopted a random mutagenesis strategy to identify EHEC genes required for colonization and survival in cattle using signature-tagged transposon mutagenesis (STM). STM makes it possible to track the fate of individually tagged bacterial transposon mutants in a complex pool during their interaction with the animal host (Hensel et al., 1995). The composition of a pool of random mutants in the inoculum can be compared with the composition of a pool of mutants recovered from the faeces at time-points after oral inoculation of calves. This involves the use of PCR and DNA hybridization to detect oligonucleotide sequence tags unique to each mutant in the pool (Hensel et al., 1995). In this way it is possible to identify EHEC transposon mutants deficient in intestinal colonization and/or survival in the bovine host. Factors required for colonization can then be identified by cloning and sequencing of the disrupted genes. Recently we have shown that mini-Tn $5 \mathrm{Km} 2$ insertions in genes encoding structural components of the LEE-encoded type III protein secretion system (escC, $e s c V$ and $e s c N)$ result in reduced faecal excretion of $E$. coli O157:H7 (P. van Diemen \& F. Dziva, unpublished observations). This finding indicates that LEE-mediated adherence of E. coli $\mathrm{O} 157: \mathrm{H} 7$ to intestinal epithelia and AE-lesion formation is important for colonization and suggests that the bacteria are not merely transient members of the lumenal microflora requiring continuous re-inoculation. The site(s) of specific adherence of E. coli $\mathrm{O} 157: \mathrm{H} 7$ to the intestinal epithelium in calves remain to be determined. LEE-encoded genes are also crucial for colonization of the rabbit intestine by rabbit EPEC (Abe et al., 1998; Marchés et al., 2000). Given that EHEC O157 and non-O157 serotypes potentially use different strategies to colonize the ruminant host we are also employing STM in an O26 calf dysentery isolate with recovery of bacterial mutants direct from the colonic mucosa. This may shed light on why some EHEC serotypes extensively interact with the intestinal epithelium whereas E. coli O157 apparently exists largely in the intestinal lumen. The information derived from screening tagged EHEC O157 and O26 transposon mutants in cattle will greatly facilitate the development of strategies to reduce the prevalence of EHEC in farm animal hosts. E. coli $\mathrm{O} 157: \mathrm{H} 7$ has been reported to undergo rapid genetic diversification following oral inoculation of calves with a single clonal isolate (Akiba et al., 2000). It is presently unclear what effect this will have on the long-term efficacy of strategies to control EHEC.

\section{Control by vaccination}

As subclinical and clinical EHEC infections in ruminants are restricted to the intestinal epithelium and lumen it is likely that a vaccine must induce high titre specific secretory $\operatorname{IgA}$ responses at the mucosal surface and/or colostral IgG responses for passive protection of the neonate. Several studies to date suggest that intimin is a good candidate antigen for inclusion in an EHEC vaccine. In a murine model of EHEC infection using the related enteropathogen Citrobacter rodentium, purified Int 280 could induce protection against $C$. rodentium infection following subcutaneous and mucosal vaccination (Ghaem-Maghami et al., 2001). Recently DeanNystrom et al. (2002) reported that vaccination of pregnant pigs with intimin from E. coli $\mathrm{O} 157: \mathrm{H} 7$ gives rise to high intimin-specific antibody titres in the serum and colostrum. Neonatal piglets allowed to suckle vaccinated dams exhibited increased resistance to colonization and intestinal damage following experimental inoculation with E. coli O157:H7 compared to piglets allowed to suckle mock-vaccinated dams (DeanNystrom et al., 2002). Recent observations by Yokomizo et al. (2002) and Ghaem-Maghami et al. (2001) suggest that it may be possible to improve the immunogenicity 
of intimin subunit vaccines using bacterial toxins as adjuvants. Intranasal administration of a truncated version of E. coli $\mathrm{O} 157: \mathrm{H} 7$ intimin to calves treated with an adjuvant comprising a detoxified derivative of E. coli heat labile enterotoxin II induced elevated IgAintimin specific antibody in nasal secretions and saliva as well as IgG1-specific antibody against intimin in the sera and colostrum of cows (Yokomizo et al., 2002). To our knowledge, the protective efficacy of these responses against oral inoculation of calves with different EHEC serotypes has not yet been tested.

Immune responses against Int 280 peptides are subtypespecific and do not protect against challenge with $C$. rodentium strains expressing heterologous intimin subtypes in the murine model (Ghaem-Maghami et al., 2001). Immunization of mice with a conserved domain of intimin (Int388-667) was not effective. Thus intiminbased vaccines may have to incorporate several different Int280 subtypes in order to protect against the predominant EHEC serotypes in cattle $(\beta, \gamma$ and $\varepsilon)$. It is possible that vaccines based on the Efa1 colonization factor may avoid complications of subtype-specificity. The Efa1 protein is expressed at the bacterial cell surface (Nicholls et al., 2000; M. Stevens, unpublished observations) and is present in all non-O157 EHEC strains tested to date (Nicholls et al., 2000; Klapproth et al., 2000). E. coli O157:H7 strains encode a truncated version of the $e f a 1$ gene encoding the $\mathrm{N}$-terminal domain of the protein. Thus subunit vaccines based on the $\mathrm{N}$ terminus of Efa1 have the potential to elicit broadly reactive immunity against all EHEC serotypes.

Conjugate and toxoid vaccines based on the 0157 lipopolysaccharide elicit specific antibody responses in mice and human volunteers (Konadu et al., 1998, 1999; Conlan et al., 1999a, 2000). However, oral and parenteral immunization of mice with an O157-glycoconjugate vaccine failed to protect against intestinal colonization with E. coli O157: H7 (Conlan et al., 1999a, 2000). Calves make O-antigen-specific antibodies in response to E. coli O157 infection (Johnson et al., 1996; Wray et al., 2000); however, the induction of the antibody response could not be correlated with clearance of the bacteria.

Butterton et al. (1997) investigated the feasibility of using a live attenuated Vibrio cholerae $\mathrm{El}$ Tor vaccine strain (Peru2) expressing the E. coli O157:H7 intimin gene for protection against EHEC in a rabbit model. A plasmid construct for the expression of eae in Peru2 proved to be unstable and failed to elicit intimin-specific antibody responses following oro-gastric inoculation of rabbits (Butterton et al., 1997). However, a Peru2 derivative with a chromosomal insertion of the eae gene induced a marked anti-Eae response in one of two rabbits. With development it should be possible to improve the expression of heterologous antigens in an appropriate bacterial carrier for cattle.

Previous studies have shown that oral vaccination of calves with a Salmonella typhimurium aro vaccine strain expressing fragment $\mathrm{C}$ of tetanus toxoid (TetC) induces potent mucosal $\operatorname{Ig} \mathrm{A}$ and serum $\operatorname{IgG}$ responses against TetC (Villareal-Ramos et al., 2000). Thus delivery of EHEC antigens by live attenuated Salmonella strains is a viable option to induce relevant EHEC-specific mucosal immunity. Salmonella strains expressing lipopolysaccharide $\mathrm{O}$-antigens of the same serogroup as prevalent EHEC isolates (O157 and O111) have been developed and offer some protection in murine models (Conlan et al., 1999b; Wang et al., 1999). Salmonella carrier vaccines have the added advantage of inducing solid protection against virulent Salmonella strains in calves (Jones et al., 1991). Live attenuated vaccines offer the advantage of in vivo amplification of the antigen, prolonged exposure of the mucosal immune system to the antigen and contact immunization via excreted organisms. However, such vaccines may be inhibited by competing organisms in the intestinal microflora and the presence of antibiotics or antibodies in the feed or milk. Further, live bacterial vaccines are unlikely to be used in food-producing animals until fears over safety and the potential for zoonotic transmission to humans are addressed. Kaper et al. (1998) suggested that 'edible vaccines' based on transgenic plants engineered to express intimin may offer another mode of delivery. Transgenic plant vaccines are capable of inducing substantial mucosal immune responses in murine models (Haq et al., 1995).

\section{Passive protection}

Antibodies directed against the carboxy-terminal domain of intimin block adherence of E. coli $\mathrm{O} 157: \mathrm{H} 7$ to cultured epithelial cells (Gansheroff et al., 1999) and mediate specific inhibition of colonization following immunization of mice with purified intimin (GhaemMaghami et al., 2001). Use of colostrum from intimin-vaccinated pigs is effective in reducing EHEC colonization and pathogenesis in piglets (Dean-Nystrom et al., 2002) and may reduce the prevalence of EHEC in younger animals. It is conceivable that recombinant antibodies directed against intimin or other EHEC colonization factors could be administered passively to food-producing farm animals or delivered in a plant vector to reduce the carriage of EHEC in the intestine prior to slaughter.

\section{Probiotics and other inhibitors}

Inhibition of EHEC proliferation in the ruminant gut may be mediated through competition for nutrients with endogenous or exogenous bacteria and/or toxic molecules. Inoculation of calves with a mixture of nonpathogenic E. coli strains and Proteus mirabilis has been reported to reduce rumen proliferation and faecal shedding of E. coli O157:H7 (Zhao et al., 1998). Probiotic mixtures based on Lactobacillus and Streptococcus spp. have also shown considerable promise in reducing intestinal colonization and faecal shedding of E. coli $\mathrm{O} 157: \mathrm{H} 7$ in experimentally infected calves (Ohya et al., 2000), sheep (Lema et al., 2001) and infant rabbits (Ogawa et al., 2001). Clearance of EHEC correlates with a marked increase in the presence of volatile fatty acids 
following inoculation with probiotic bacteria and occurred in young animals with a relatively undeveloped gut microflora. In adult ruminants lactic-acid-producing bacteria are a very minor constituent of the intestinal microflora and so may be less effective or require frequent re-inoculation. Nevertheless, administration of probiotic bacteria to reduce the carriage of EHEC prior to slaughter may significantly reduce the introduction of EHEC into the human food chain. Pseudomonas aeruginosa strains inhibitory to E. coli $\mathrm{O} 157: \mathrm{H} 7$ have been isolated from the rumens of sheep (Duncan et al., 1999); however, to our knowledge the ability of these bacteria to inhibit EHEC infection in ruminants has not been tested. Lytic bacteriophages that specifically target EHEC expressing the O157 antigen and colicins active on EHEC have also been isolated and may be useful for the control of E. coli $\mathrm{O} 157: \mathrm{H} 7$ in ruminants prior to slaughter (Murinda et al., 1996; Kudva et al., 1999). It is unlikely that such agents could be effective long term owing to the development of genetic resistance. The possible use of non-therapeutic compounds to create an intestinal environment unfavourable to EHEC is reviewed elsewhere (Duncan et al., 2000).

\section{Effect of diet and fasting}

Several studies indicate that it may be possible to reduce the carriage of EHEC by calves and sheep by manipulating the diet. Diet and the feeding regime may influence growth and survival of EHEC in the ruminant intestine by creating fermentation conditions that give rise to elevated volatile fatty acid concentrations, adverse $\mathrm{pH}$ and/or changes in the composition of the resident microflora (Duncan et al., 2000; Russell et al., 2000). Further, different diets may influence the magnitude and duration of shedding of EHEC by altering the rate of epithelial cell proliferation in the lower gastrointestinal tract (Magnuson et al., 2000).

Reports on the effect of diet and diet shifts on shedding of E. coli $\mathrm{O} 157: \mathrm{H} 7$ in ruminants are often conflicting. Grain feeding has been proposed as a risk factor for increased shedding of EHEC in cattle (Diez-Gonzalez et al., 1998; Dargatz et al., 1997). However, Hancock et al. (1994) and Magnuson et al. (2000) found no difference in the amount or duration of E. coli $\mathrm{O} 157: \mathrm{H} 7$ shedding between animals fed grain and forage diets. Indeed, grain-fed sheep shed E. coli O157:H7 for a significantly shorter duration under some conditions than sheep fed hay (Kudva et al., 1997). Experimentally inoculated calves fed on a primarily grain-based diet develop a lower rumen $\mathrm{pH}$ and shed elevated numbers of acidtolerant E. coli O157:H7 than calves fed on a highroughage (hay-based) diet (Diez-Gonzalez et al., 1998; Tkalcic et al., 2000). Acid-tolerant EHEC may be expected to colonize other animals, and possibly humans, more efficiently since they may survive better in the acidic compartments of the intestine. Thus grain diets may actually facilitate transmission of the bacteria in the farm environment. A brief period of feeding hay to grain-fed calves has been reported to decrease the number of acid-resistant E. coli $\mathrm{O} 157: \mathrm{H} 7$ shed sub- stantially (Diez-Gonzalez et al., 1998) and may help to reduce entry of acid-resistant EHEC into the food chain. However, Hovde et al. (1999) found that hay-fed animals shed E. coli O157:H7 for longer than grain-fed animals, and that irrespective of diet, equal numbers of acidresistant EHEC were shed. Further studies are required to determine the influence of different diets on the shedding and infectivity of EHEC in ruminants.

Other foodstuffs including cottonseed, clover or lucerne hay and soymeal have been reported to reduce the shedding of $E$. coli in cattle (Brownlie \& Grau, 1967; Dargatz et al., 1997; Garber et al., 1995), while barley (Dargatz et al., 1997), corn silage (Herriott et al., 1998) and beetpulp (Schouten et al., 2001) appear to increase carriage rates. The relative abundance in plants of secondary metabolites inhibitory to EHEC may play a role in this (Duncan et al., 2000).

Fasting is common before and during transportation of animals to abattoirs and is intended to reduce soiling of the hide. This practice may inadvertently increase the proliferation of EHEC in the intestine by causing the rumen $\mathrm{pH}$ to rise and the concentration of volatile fatty acids to drop (Duncan et al., 2000). Cray et al. (1998) reported that withholding food for $48 \mathrm{~h}$ prior to inoculation rendered calves more susceptible to $E$. coli O157: H7 infection and that significantly more bacteria were shed compared with animals fed without interruption. Similar observations have been made in rams deprived of feed and water (Kudva et al., 1995). Withdrawal of food from calves carrying EHEC has been shown to increase faecal shedding in some previously low-shedding calves (Brown et al., 1997), and was variable in calves shedding larger populations (Brown et al., 1997). However, Cray et al. (1998) found no effect on shedding levels of withdrawing feed after $E$. coli $\mathrm{O} 157: \mathrm{H} 7$ infection of calves. An important consideration when comparing the results of such studies may be the accuracy of quantification of EHEC excretion rates and the possible influence of water content on the count of bacteria per unit weight of sample.

\section{Impact of farm management practices}

Considerable effort has been expended to identify herd management practices and environmental factors that inhibit or facilitate infection of animals with E. coli O157:H7 (reviewed by Hancock et al., 1998). EHEC transmit readily between ruminants in the farm environment (Besser et al., 2001), and wild animals may represent important vectors. Environmental factors that may influence E. coli O157: $\mathrm{H} 7$ shedding in cattle include livestock feed (see above) and waste-handling practices (Kudva et al., 1998), presence of non-farm animals in the location of the herd (Schouten et al., 2001) as well as insects and microbial interactions in soil and water (Rasmussen \& Casey, 2001). Provision of potable water, clean feed, adequate bedding and clean accommodation should help to reduce within-herd transmission of EHEC. Measures to control EHEC at slaughter are described elsewhere (Gannon, 1999). Elimination of 
EHEC by testing and removal of infected animals would appear to be impractical since the majority of herds are infected at some time.

\section{Perspective}

Although the incidence of human EHEC infection is relatively low, the severity of the symptoms and frequency of renal and neurological sequelae give cause for concern. The disease has a high public profile and there is a pressing demand for the development of treatment and/or prevention strategies. Considerable progress has been made in understanding the ecology of EHEC in farm animal hosts and the modes of transmission to humans. It remains unclear if all EHEC present in animal reservoirs present a risk to human health and further studies are required on the genetic stability of EHEC during their interaction with ruminants. Strategies to reduce the prevalence of EHEC in ruminants offer the potential to lower the incidence of human infection. Probiotics, bacteriophages and feeding regimes that create an intestinal environment inhibitory to EHEC may prove to be useful prior to slaughter to reduce the entry of EHEC into the food chain. Given the extremely low infectious dose for humans, it is open to question whether such strategies can reduce the shedding of EHEC by the amount needed to significantly reduce the risk to human health. Further research is required on the mechanisms underlying EHEC-intestinal colonization and enteropathogenesis in cattle and sheep and the host responses to infection. Insights gained from the genome sequence of E. coli $\mathrm{O} 157: \mathrm{H} 7$ and from screening defined and signature-tagged transposon EHEC mutants in experimental animal models will add greatly to our understanding of these processes. This information will be crucial for the design of vaccines or other intervention measures.

\section{Acknowledgements}

The authors gratefully acknowledge the support of the BBSRC (grant numbers 201/10261 and 201/17455), European Union (QLK2-2000-00600) and the Department for the Environment and Rural Affairs (OZ0707).

\section{References}

Abe, A., Heczko, U., Hegele, H. G. \& Finlay, B. B. (1998). Two enteropathogenic Escherichia coli type III secreted proteins, EspA and EspB, are virulence factors. J Exp Med 188, 1907-1916.

Adu-Bobie, J., Frankel, G., Bain, C., Goncaleves, A. G., Trabulsi, L. R., Douce, G., Knutton, S. \& Dougan, G. (1998). Detection of intimin $\alpha, \beta, \gamma$, and $\delta$, four derivatives expressed by attaching and effacing microbial pathogens. J Clin Microbiol 36, 662-668.

Akiba, M., Sameshima, T. \& Nakazawa, M. (2000). Clonal turnover of enterohemorrhagic Escherichia coli O157:H7 in experimentally infected cattle. FEMS Microbiol Lett 184, 79-83.

Allen-Vercoe, E., Sayers, A. R. \& Woodward, M. J. (1999). Virulence of Salmonella enterica serotype Enteritidis aflagellate and afimbriate mutants in a day-old chick model. Epidemiol Infect 122, 395-402.

Anon (1998). Vero cytotoxin producing Escherichia coli in England and Wales. Commun Dis Rep Wkly 8, 169.
Anon (2000). Surveillance of vero cytotoxin producing Escherichia coli O157 in England and Wales. Commun Dis Rep Wkly 10, 171.

Armstrong, G. L., Hollingsworth, J. \& Morris, J. G., Jr (1996). Emerging foodborne pathogens: Escherichia coli $\mathrm{O} 157: \mathrm{H} 7$ as a model of entry of a new pathogen into the food supply of the developed world. Epidemiol Rev 18, 29-51.

Besser, T. E., Richards, B. L., Rice, D. H. \& Hancock, D. D. (2001). Escherichia coli $\mathrm{O} 157: \mathrm{H} 7$ infection of calves: infectious dose and direct contact transmission. Epidemiol Infect 127, 555-560.

Bettelheim, K. A. (2000). Role of non-O157 VTEC. Symp Ser Soc Appl Microbiol 29, 38S-50S.

Brown, C. A., Harmon, B. G., Zhao, T. \& Doyle, M. P. (1997). Experimental Escherichia coli $\mathrm{O} 157: \mathrm{H} 7$ carriage in calves. Appl Environ Microbiol 63, 27-32.

Brownlie, L. E. \& Grau, F. H. (1967). Effect of food intake on the growth and survival of Salmonellas and Escherichia coli in the bovine rumen. J Gen Microbiol 46, 125-134.

Butterton, J. R., Ryan, E. T., Acheson, D. W. \& Calderwood, S. B. (1997). Coexpression of the B subunit of Shiga toxin 1 and EaeA from enterohemorrhagic Escherichia coli in Vibrio cholerae vaccine strains. Infect Immun 65, 2127-2135.

Chanter, N., Hall, G. A., Bland, A. P., Hayle, A. J. \& Parsons, K. R. (1986). Dysentery in calves caused by an atypical strain of Escherichia coli (S102-9). Vet Microbiol 12, 241-253.

Cody, S. H., Glynn, M. K., Farrar, J. A. \& 10 other authors (1999). An outbreak of Escherichia coli O157:H7 infection from unpasteurized commercial apple juice. Ann Intern Med 130, 202-209.

Conlan, J. W., Cox, A. D., Kuolee, R., Webb, A. \& Perry, M. B. (1999a). Parenteral immunization with a glycoconjugate vaccine containing the $\mathrm{O} 157$ antigen of Escherichia coli O157:H7 elicits a systemic humoral immune response in mice, but fails to prevent colonization by the pathogen. Can J Microbiol 45, 279-286.

Conlan, J. W., KuoLee, R., Webb, A. \& Perry, M. B. (1999b). Salmonella landau as a live vaccine against Escherichia coli O157:H7 investigated in a mouse model of intestinal colonization. Can J Microbiol 45, 723-731.

Conlan, J. W., Kuolee, R., Webb, A., Cox, A. D. \& Perry, M. B. (2000). Oral immunization of mice with a glycoconjugate vaccine containing the $\mathrm{O} 157$ antigen of Escherichia coli O157:H7 admixed with cholera toxin fails to elicit protection against subsequent colonization by the pathogen. Can J Microbiol 46, 283-290.

Cornick, N. A., Booher, S. L., Casey, T. A. \& Moon, H. W. (2000). Persistent colonization of sheep by Escherichia coli $\mathrm{O} 157: \mathrm{H} 7$ and other E. coli pathotypes. Appl Environ Microbiol 66, 4926-4934.

Cornick, N. A., Booher, S. L. \& Moon, H. W. (2002). Intimin facilitates colonization by Escherichia coli O157:H7 in adult ruminants. Infect Immun 70, 2704-2707.

Cray, W. C., Jr \& Moon, H. W. (1995). Experimental infection of calves and adult cattle with Escherichia coli O157:H7. Appl Environ Microbiol 61, 1586-1590.

Cray, W. C., Jr, Casey, T. A., Bosworth, B. T. \& Rasmussen, M. A. (1998). Effect of dietary stress on fecal shedding of Escherichia coli O157:H7 in calves. Appl Environ Microbiol 64, 1975-1979.

Dargatz, D. A., Wells, S. J., Thomas, L. A., Hancock, D. D. \& Garber, L. P. (1997). Factors associated with the presence of Escherichia coli $\mathrm{O} 157$ in faeces of feedlot cattle. J Food Protein 5, 466-470.

Dean-Nystrom, E. A., Bosworth, B. T., Cray, W. C., Jr \& Moon, H. W. (1997). Pathogenicity of Escherichia coli O157:H7 in the intestines of neonatal calves. Infect Immun 65, 1842-1848. 
Dean-Nystrom, E. A., Bosworth, B. T., Moon, H. W. \& O'Brien, A. D. (1998a). Bovine infection with Shiga toxin-producing Escherichia coli. In Escherichia coli O157:H7 and Other Shiga Toxin-producing Escherichia coli, pp. 261-267. Edited by J. B. Kaper \& A. D. O’Brien. Washington, DC: American Society for Microbiology.

Dean-Nystrom, E. A., Bosworth, B. T., Moon, H. W. \& O'Brien, A. D. (1998b). Escherichia coli $\mathrm{O} 157: \mathrm{H} 7$ requires intimin for enteropathogenicity in calves. Infect Immun 66, 4560-4563.

Dean-Nystrom, E. A., Bosworth, B. T. \& Moon, H. W. (1999). Pathogenesis of Escherichia coli O157:H7 in weaned calves. Adv Exp Med Biol 473, 173-177.

Dean-Nystrom, E. A., Gansheroff, L. J., Mills, M., Moon, H. W. \& O'Brien, A. D. (2002). Vaccination of pregnant dams with intimin(O157) protects suckling piglets from Escherichia coli O157: H7 infection. Infect Immun 70, 2414-2418.

DeVinney, R., Stein, M., Reinscheid, D., Abe, A., Ruschkowski, S. \& Finlay, B. B. (1999). Enterohemorrhagic Escherichia coli O157:H7 produces Tir, which is translocated to the host cell membrane but is not tyrosine phosphorylated. Infect Immun 67, 2389-2398.

Diez-Gonzalez, F., Callaway, T. R., Kizoulis, M. G. \& Russell, J. B. (1998). Grain feeding and the dissemination of acid-resistant Escherichia coli from cattle. Science 281, 1666-1668.

Donnenberg, M. S., Tzipori, S. S., McKee, M. L., O’Brien, A. D., Alroy, J. \& Kaper, J. B. (1993). Role of the eae gene of enterohaemorrhagic Escherichia coli in intimate attachment in vitro and in a porcine model. J Clin Invest 92, 1418-1424.

Duncan, S. H., Doherty, C. J., Govan, J. R., Neogrady, S., Galfi, P. \& Stewart, C. S. (1999). Characteristics of sheep-rumen isolates of Pseudomonas aeruginosa inhibitory to the growth of Escherichia coli O157. FEMS Microbiol Lett 180, 305-310.

Duncan, S. H., Booth, I. R., Flint, H. J. \& Stewart, C. S. (2000). The potential for the control of Escherichia coli O157 in farm animals. Symp Ser Soc Appl Microbiol 29, 157S-165S.

Ebel, F., Podzadel, T., Rohde, M., Kresse, A. U., Krämer, S., Deibel, C., Guzmán, C. A. \& Chakraborty, T. (1998). Initial binding of Shiga toxin-producing Escherichia coli to host cells and subsequent induction of actin rearrangements depend on filamentous EspA-containing surface appendages. Mol Microbiol 30, 147-161.

Elder, R. O., Keen, J. E., Siragusa, G. R., Barkocy-Gallagher, G. A., Koohmaraie, M. \& Laegreid, W. W. (2000). Correlation of enterohemorrhagic Escherichia coli O157 prevalence in feces, hides, and carcasses of beef cattle during processing. Proc Natl Acad Sci US A 97, 2999-3003.

Ferens, W. A. \& Hovde, C. J. (2000). Antiviral activity of Shiga toxin 1: suppression of bovine leukemia virus-related spontaneous lymphocyte proliferation. Infect Immun 68, 4462-4469.

Fitzhenry, R. J., Pickard, D. J., Hartland, E. L., Reece, S., Dougan, G., Phillips, A. D. \& Frankel, G. (2002). Intimin type influences the site of human intestinal mucosal colonisation by enterohaemorrhagic Escherichia coli O157:H7. Gut 50, 180-185.

Frankel, G., Candy, D. C., Everest, P. \& Dougan, G. (1994). Characterization of the C-terminal domains of intimin-like proteins of enteropathogenic and enterohemorrhagic Escherichia coli, Citrobacter freundii, and Hafnia alvei. Infect Immun 62, 1835-1842.

Frankel, G., Lider, O., Hershkoviz, R., Mould, A. P., Kachalsky, S. G., Candy, D. C. A., Cahalon, L., Humphries, M. J. \& Dougan, G. (1996). The cell-binding domain of intimin from enteropathogenic Escherichia coli binds to beta1 integrins. J Biol Chem 271, 20359-20364.
Frankel, G., Phillips, A. D., Rosenshine, I., Dougan, G., Kaper, J. B. \& Knutton, S. (1998). Enteropathogenic and enterohaemorrhagic Escherichia coli: more subversive elements. Mol Microbiol 30, 911-921.

Gannon, V. P. J. (1999). Control of Escherichia coli at slaughter. In Escherichia coli O157 in Farm Animals, pp. 169-193. Edited by C. S. Stewart \& H. J. Flint. Wallingford: CAB International.

Gansheroff, L. J. \& O’Brien, A. D. (2000). Escherichia coli O157: H7 in beef cattle presented for slaughter in the U.S. : higher prevalence rates than previously estimated. Proc Natl Acad Sci US A 97, 2959-2961.

Gansheroff, L. J., Wachtel, M. R. \& O’Brien, A. D. (1999). Decreased adherence of enterohemorrhagic Escherichia coli to HEp2 cells in the presence of antibodies that recognize the C-terminal region of intimin. Infect Immun 67, 6409-6417.

Garber, L. P., Wells, S. J., Hancock, D. D., Doyle, M. P., Tuttle, J., Shere, J. A. \& Zhao, T. (1995). Risk factors for fecal shedding of Escherichia coli O157: $\mathrm{H} 7$ in dairy calves. J Am Vet Med Assoc 207, 46-49.

Ghaem-Maghami, M., Simmons, C. P., Daniell, S., Pizza, M., Lewis, D., Frankel, G. \& Dougan, G. (2001). Intimin-specific immune responses prevent bacterial colonization by the attaching-effacing pathogen Citrobacter rodentium. Infect Immun 69, 5597-5605.

Girón, J. A., Torres, A. G., Freer, E. \& Kaper, J. B. (2002). The flagella of enteropathogenic Escherichia coli mediate adherence to epithelial cells. Mol Microbiol 44, 361-379.

Grauke, L. J., Kudva, I. T., Yoon, J. W., Hunt, C. W., Williams, C. J. \& Hovde, C. J. (2002). Gastrointestinal tract location of Escherichia coli $\mathrm{O} 157: \mathrm{H} 7$ in ruminants. Appl Environ Microbiol 68, 2269-2277.

Griffin, P. M. (1995). Escherichia coli O157:H7 and other enterohaemorrhagic Escherichia coli. In Infections of the Gastrointestinal Tract, pp. 739-761. Edited by M. J. Blaser, P. D. Smith, J. I. Ravdin, H. B. Greenberg \& R. L. Guerrant. New York: Raven Press.

Hall, G. A., Reynolds, D. J., Chanter, N., Morgan, J. H., Parsons, K. R., Debney, T. G., Bland, A. P. \& Bridger, J. C. (1985). Dysentery caused by Escherichia coli (S102-9) in calves: natural and experimental disease. Vet Pathol 22, 156-163.

Hancock, D. D., Besser, T. E., Kinsel, M. L., Tarr, P. I., Rice, D. H. \& Paros, M. G. (1994). The prevalence of Escherichia coli O157:H7 in dairy and beef cattle in Washington State. Epidemiol Infect 113, 119-207.

Hancock, D. D., Besser, T. E. \& Rice, D. H. (1998). Ecology of Escherichia coli O157:H7 in cattle and impact of management practices. In Escherichia coli O157:H7 and other Shiga Toxinproducing Escherichia coli, pp. 85-91. Edited by J. B. Kaper \& A. D. O’Brien. Washington, DC: American Society for Microbiology.

Haq, T. A., Mason, H. S., Clements, J. D. \& Arntzen, C. J. (1995). Oral immunization with a recombinant bacterial antigen produced in transgenic plants. Science 268, 714-716.

Hayashi, T., Makino, K., Ohnishi, M. \& 19 other authors (2001). Complete genome sequence of enterohemorrhagic Escherichia coli $\mathrm{O} 157: \mathrm{H} 7$ and genomic comparison with a laboratory strain K-12. DNA Res 8, 11-22.

Hensel, M., Shea, J. E., Gleeson, C., Jones, M. D., Dalton, E. \& Holden, D. W. (1995). Simultaneous identification of bacterial virulence genes by negative selection. Science 269, 400-403.

Herriott, D. E., Hancock, D. D., Ebel, E. D., Carpenter, L. V., Rice, D. H. \& Besser, T. E. (1998). Association of herd management 
factors with colonization of dairy cattle by Shiga toxin-positive Escherichia coli O157. J Food Protein 61, 802-807.

Hilborn, E. D., Mermin, J. H., Mshar, P. A. \& 9 other authors (1999). A multistate outbreak of Escherichia coli O157:H7 infections associated with consumption of mesclun lettuce. Arch Intern Med 159, 1758-1764.

Hoey, D. E., Currie, C., Else, R. W., Nutikka, A., Lingwood, C. A., Gally, D. L. \& Smith, D. G. (2002). Expression of receptors for verotoxin 1 from Escherichia coli $\mathrm{O} 157$ on bovine intestinal epithelium. J Med Microbiol 51, 143-149.

Hovde, C. J., Austin, P. R., Cloud, K. A., William, C. J. \& Hunt, C. W. (1999). Effect of cattle diet on Escherichia coli O157:H7 acid resistance. Appl Environ Microbiol 65, 3233-3235.

Jenkins, C., Chart, H., Cheasty, T. \& 8 other authors (2002). Verocytotoxin-producing Escherichia coli (VTEC) other than serogroup O157 from Scottish cattle. Vet Rec 15, 58-60.

Johnson, R. P., Cray, W. C., Jr \& Johnson, S. T. (1996). Serum antibody responses of cattle following experimental infection with Escherichia coli O157: H7. Infect Immun 64, 1879-1883.

Jones, P. W., Dougan, G., Hayward, C., Mackensie, N., Collins, P. \& Chatfield, S. N. (1991). Oral vaccination of calves against experimental salmonellosis using a double aro mutant of Salmonella typhimurium. Vaccine 9, 29-34.

Kaper, J. B., Gansheroff, L. J., Wachtel, M. R. \& O’Brien, A. D. (1998). Intimin-mediated adherence of Shiga toxin-producing Escherichia coli and attaching-and-effacing pathogens. In Escherichia coli O157:H7 and Other Shiga Toxin-producing Escherichia coli, pp. 148-156. Edited by J. B. Kaper \& A. D. O’Brien. Washington, DC: American Society for Microbiology.

Klapproth, J. M., Donnenberg, M. S., Abraham, J. M. \& James, S. P. (1996). Products of enteropathogenic E. coli inhibit lymphokine production by gastrointestinal lymphocytes. Am J Physiol 271, G841-848.

Klapproth, J. M., Scaletsky, I. C., McNamara, B. P., Lai, L. C., Malstrom, C., James, S. P. \& Donnenberg, M. S. (2000). A large toxin from pathogenic Escherichia coli strains that inhibits lymphocyte activation. Infect Immun 68, 2148-2155.

Kobayashi, H., Shimada, J., Nakazawa, M., Morozumi, T., Pohjanvirta, T., Pelkonen, S. \& Yamamoto, K. (2001). Prevalence and characteristics of Shiga toxin-producing Escherichia coli from healthy cattle in Japan. Appl Environ Microbiol 67, 484-489.

Konadu, E. Y., Parke, J. C., Jr, Tran, H. T., Bryla, D. A., Robbins, J. B. \& Szu, S. C. (1998). Investigational vaccine for Escherichia coli O157: phase 1 study of O157 O-specific polysaccharidePseudomonas aeruginosa recombinant exoprotein A conjugates in adults. J Infect Dis 177, 383-387.

Konadu, E., Donohue-Rolfe, A., Calderwood, S. B., Pozsgay, V., Shiloach, J., Robbins, J. B. \& Szu, S. C. (1999). Syntheses and immunologic properties of Escherichia coli O157 O-specific polysaccharide and Shiga toxin $1 \mathrm{~B}$ subunit conjugates in mice. Infect Immun 67, 6191-6193.

Kudva, I. T., Hatfield, P. G. \& Hovde, C. J. (1995). Effect of diet on the shedding of Escherichia coli O157:H7 in a sheep model. Appl Environ Microbiol 61, 1363-1370.

Kudva, I. T., Hunt, C. W., Williams, C. J., Nance, U. M. \& Hovde, C. J. (1997). Evaluation of dietary influences on Escherichia coli O157:H7 shedding by sheep. Appl Environ Microbiol 63, 3878-3886.

Kudva, I. T., Blanch, K. \& Hovde, C. J. (1998). Analysis of Escherichia coli O157: $\mathrm{H} 7$ survival in ovine or bovine manure and manure slurry. Appl Environ Microbiol 64, 3166-3174.

Kudva, I. T., Jelacic, S., Tarr, P. I., Youderian, P. \& Hovde, C. J.
(1999). Biocontrol of Escherichia coli O157 with O157-specific bacteriophages. Appl Environ Microbiol 65, 3767-3773.

La Ragione, R. M., Sayers, A. R. \& Woodward, M. J. (2000). The role of fimbriae and flagella in the colonization, invasion and persistence of Escherichia coli O78:K80 in the day-old-chick model. Epidemiol Infect 124, 351-363.

Lema, M., Williams, L. \& Rao, D. R. (2001). Reduction of fecal shedding of enterohemorrhagic Escherichia coli O157:H7 in lambs by feeding microbial feed supplement. Small Ruminant Res 39, 31-39.

Locking, M. E., O'Brien, S. J., Reilly, W. J., Wright, E. M., Campbell, D. M., Coia, J. E., Browning, L. M. \& Ramsay, C. N. (2001). Risk factors for sporadic cases of Escherichia coli O157 infection: the importance of contact with animal excreta. Epidemiol Infect 127, 215-220.

Magnuson, B. A., Davis, M., Hubele, S., Austin, P. R., Kudva, I. T., Williams, C. J., Hunt, C. W. \& Hovde, C. J. (2000). Ruminant gastrointestinal cell proliferation and clearance of Escherichia coli O157: H7. Infect Immun 68, 3808-3814.

Mainil, J. (1999). Shiga/verocytotoxins and Shiga/verotoxigenic Escherichia coli in animals. Vet Res 30, 235-257.

Malstrom, C. \& James, S. (1995). Inhibition of murine splenic and mucosal lymphocyte function by enteric bacterial products. Infect Immun 66, 3120-3127.

Marchés, O., Nougayrède, J.-P., Boullier, S. \& 8 other authors (2000). Role of Tir and intimin in the virulence of rabbit enteropathogenic Escherichia coli serotype O103:H2. Infect Immun 68, 2171-2182.

McKee, M. L., Melton-Celsa, A. R., Moxley, R. A., Francis, D. H. \& O'Brien, A. D. (1995). Enterohaemorrhagic Escherichia coli O157:H7 requires intimin to colonize the gnotobiotic pig intestine and to adhere to HEp-2 cells. Infect Immun 63, 3739-3744.

McNally, A., Roe, A. J., Simpson, S., Thomson-Carter, F. M., Hoey, D. E., Currie, C., Chakraborty, T., Smith, D. G. \& Gally, D. L. (2001). Differences in levels of secreted locus of enterocyte effacement proteins between human disease-associated and bovine Escherichia coli O157. Infect Immun 69, 5107-5114.

Menge, C., Wieler, L. H., Schlapp, T. \& Baljer, G. (1999). Shiga toxin 1 from Escherichia coli blocks activation and proliferation of bovine lymphocyte subpopulations in vitro. Infect Immun 67, 2209-2217.

Murinda, S. E., Roberts, R. F. \& Wilson, R. A. (1996). Evaluation of colicins for inhibitory activity against diarrheagenic Escherichia coli strains, including serotype O157:H7. Appl Environ Microbiol 62, 3196-3202.

Nataro, J. P. \& Kaper, J. B. (1998). Diarrheagenic Escherichia coli. Clin Microbiol Rev 11, 142-201.

Nicholls, L., Grant, T. H. \& Robins-Browne, R. M. (2000). Identification of a novel genetic locus that is required for in vitro adhesion of a clinical isolate of enterohaemorrhagic Escherichia coli to epithelial cells. Mol Microbiol 35, 275-288.

O'Brien, S. J., Adak, G. K. \& Gilham, C. (2001). Contact with farming environment as a major risk factor for Shiga toxin (Verocytotoxin)-producing Escherichia coli O157 infection in humans. Emerg Infect Dis 7, 1049-1051.

Ogawa, M., Shimizu, K., Nomoto, K. \& 7 other authors (2001). Protective effect of Lactobacillus casei strain Shirota on Shiga toxin-producing Escherichia coli O157:H7 infection in infant rabbits. Infect Immun 69, 1101-1108.

Ogden, I. D., Hepburn, N. F., MacRae, M., Strachan, N. J., Fenlon, D. R., Rusbridge, S. M. \& Pennington, T. H. (2002). Long-term 
survival of Escherichia coli O157 on pasture following an outbreak associated with sheep at a scout camp. Lett Appl Microbiol 34, 100-104.

Ohya, T., Marubashi, T. \& Ito, H. (2000). Significance of fecal volatile fatty acids in shedding of Escherichia coli O157 from calves: experimental infection and preliminary use of a probiotic product. J Vet Med Sci 62, 1151-1155.

Olsen, S. J., Miller, G., Kennedy, M., Higgins, C., Walford, J., McKee, G., Fox, K., Bibb, W. \& Mead, P. (2002). A waterborne outbreak of Escherichia coli O157:H7 infections and hemolytic uremic syndrome: implications for rural water systems. Emerg Infect Dis 8, 370-375.

Paiba, G. A., Gibbens, J. C., Pascoe, S. J. S. \& 12 other authors (2002). Faecal carriage of verotoxin-producing Escherichia coli O157 in cattle and sheep at slaughter in Great Britain. Vet Rec 150, 593-598.

Paton, A. W., Woodrow, M. C., Doyle, R. M., Lanser, J. A. \& Paton, J. C. (1999). Molecular characterization of a Shiga toxigenic Escherichia coli O113:H21 strain lacking eae responsible for a cluster of cases of hemolytic-uremic syndrome. J Clin Microbiol 37, 3357-3361.

Paton, A. W., Srimanote, P., Woodrow, M. C. \& Paton, J. C. (2001). Characterization of Saa, a novel autoagglutinating adhesin produced by locus of enterocyte effacement-negative Shigatoxigenic Escherichia coli strains that are virulent for humans. Infect Immun 69, 6999-7009.

Paton, J. C. \& Paton, A. W. (1998). Pathogenesis and diagnosis of Shiga-toxin producing Escherichia coli infections. Clin Microbiol Rev 11, 450-479.

Pearson, G. R., Bazeley, K. J., Jones, J. R., Gunning, R. F., Green, M. J., Cookson, A. \& Woodward, M. J. (1999). Attaching and effacing lesions in the large intestine of an eight-month-old heifer associated with Escherichia coli O26 infection in a group of animals with dysentery. Vet Rec 145, 370-373.

Perna, N. T., Plunkett, G., Burland, V. \& 25 other authors (2001). Genome sequence of enterohaemorrhagic Escherichia coli O157: H7. Nature 409, 529-533.

Phillips, A. D. \& Frankel, G. (2000). Intimin-mediated tissue specificity in enteropathogenic Escherichia coli interaction with human intestinal organ cultures. J Infect Dis 181, 1496-1500.

Pritchard, G. C., Williamson, S., Carson, T., Bailey, J. R., Warne, L., Willshaw, G. \& Cheasty, T. (2001). Wild rabbits - a novel vector for verocytotoxigenic Escherichia coli O157. Vet Rec 149, 567.

Rasmussen, M. A. \& Casey, T. A. (2001). Environmental and food safety aspects of Escherichia coli O157:H7 infections in cattle. Crit Rev Microbiol 27, 57-73.

Roe, A. J. \& Gally, D. L. (2000). Enteropathogenic and enterohaemorrhagic Escherichia coli and diarrhoea. Curr Opin Infect Dis 13, 511-517.

Roe, A. J., Currie, C., Smith, D. G. \& Gally, D. L. (2001). Analysis of type 1 fimbriae expression in verotoxigenic Escherichia coli: a comparison between serotypes O157 and O26. Microbiology 147, 145-152.

Russell, J. B., Diez-Gonzalez, F. \& Jarvis, G. N. (2000). Potential effect of cattle diets on the transmission of pathogenic Escherichia coli to humans. Microbes Infect 2, 45-53.

Sanderson, M. W., Besser, T. E., Gay, J. M., Gay, C. C. \& Hancock, D. D. (1999). Fecal Escherichia coli O157:H7 shedding patterns of orally inoculated calves. Vet Microbiol 69, 199-205.

Sandhu, K. S. \& Gyles, C. L. (2002). Pathogenic Shiga toxinproducing Escherichia coli in the intestine of calves. Can J Vet Res 66, 65-72.
Sandhu, K. S., Clarke, R. C., McFadden, K., Brouwer, A., Louie, M., Wilson, J., Loir, H. \& Gyles, C. L. (1996). Prevalence of the eaeA gene in verotoxigenic Escherichia coli strains from dairy cattle in Southwest Ontario. Epidemiol Infect 116, 1-7.

Schouten, J. M., Bouwknegt, M., van de Giessen, A. W., Frankena, K. \& Graat, E. A. M. (2001). Risk factor analysis of Escherichia coli $\mathrm{O} 157$ on Dutch dairy farms: preliminary results. In Proceedings of the Society for Veterinary Epidemiology and Preventive Medicine, pp. 202-210. Edited by F. D. Menzies \& S. W. J. Reid. Noordwijkerhout, NL.

Sinclair, J. F. \& O'Brien, A. D. (2002). Cell surface-localized nucleolin is a eukaryotic receptor for the adhesin intimin-gamma of enterohemorrhagic Escherichia coli O157:H7. J Biol Chem 277, 2876-2885.

Slutsker, L., Ries, A. A., Greene, K. D., Wells, J. G., Hutwagner, L. \& Griffin, P. M. (1997). Escherichia coli O157:H7 diarrhea in the United States: clinical and epidemiological features. Ann Intern Med 126, 505-513.

Srimanote, P., Paton, A. W. \& Paton, J. C. (2002). Characterization of a novel type IV pilus locus encoded on the large plasmid of locus of enterocyte effacement-negative Shiga-toxigenic Escherichia coli strains that are virulent for humans. Infect Immun 70, 3094-3100.

Stevens, M. P., Marchés, O., Campbell, J., Huter, V., Frankel, G., Phillips, A. D., Oswald, E. \& Wallis, T. S. (2002a). Intimin, Tir and Shiga toxin 1 do not influence enteropathogenic responses to Shiga toxin-producing Escherichia coli in bovine ligated intestinal loops. Infect Immun 70, 945-952.

Stevens, M. P., van Diemen, P. M., Frankel, G., Phillips, A. D. \& Wallis, T. S. (2002b). Efa1 influences colonisation of the bovine intestine by Shiga toxin-producing Escherichia coli serotypes O5 and O111. Infect Immun 70, 5158-5166.

Tarr, P. I., Bilge, S. S., Vary, J. C., Jr, Jelacic, S., Habeeb, R. L., Ward, T. R., Baylor, M. R. \& Besser, T. E. (2000). Iha: a novel Escherichia coli O157:H7 adherence-conferring molecule encoded on a recently acquired chromosomal island of conserved structure. Infect Immun 68, 1400-1407.

Tatsuno, I., Kimura, H., Okutani, A. \& 10 other authors (2000). Isolation and characterization of mini- $\mathrm{Tn} 5 \mathrm{Km} 2$ insertion mutants of enterohemorrhagic Escherichia coli O157:H7 deficient in adherence to Caco-2 cells. Infect Immun 68, 5943-5952.

Tatsuno, I., Horie, M., Abe, H. \& 7 other authors (2001). to $x B$ gene on pO157 of enterohaemorrhagic Escherichia coli O157:H7 is required for full epithelial cell adherence phenotype. Infect Immun 69, 6660-6669.

Tkalcic, S., Brown, C. A., Harmon, B. G. \& 7 other authors (2000). Effects of diet on rumen proliferation and fecal shedding of Escherichia coli O157: H7 in calves. J Food Protein 63, 1630-1636.

Tzipori, S., Gunzer, F., Donnenberg, M. S., de Montigny, L., Kaper, J. B. \& Donohue-Rolfe, A. (1995). The role of the eaeA gene in diarrhea and neurological complications in a gnotobiotic piglet model of enterohaemorrhagic Escherichia coli infection. Infect Immun 63, 3621-3627.

Villarreal-Ramos, B., Manser, J. M., Collins, R. A., Dougan, G. \& Howard, C. J. (2000). Cattle immune responses to tetanus toxoid elicited by recombinant $S$. typhimurium vaccines or tetanus toxoid in alum or Freund's adjuvant. Vaccine 18, 1515-1521.

Wales, A. D., Clifton-Hadley, F. A., Cookson, A. L., Dibb-Fuller, M. P., La Ragione, R. M., Sprigings, K. A., Pearson, G. R. \& Woodward, M. J. (2001a). Experimental infection of six-monthold sheep with Escherichia coli O157:H7. Vet Rec 148, 630-631.

Wales, A. D., Pearson, G. R., Skuse, A. M., Roe, J. M., Hayes, 
C. M., Cookson, A. L. \& Woodward, M. J. (2001b). Attaching and effacing lesions caused by Escherichia coli O157:H7 in experimentally inoculated neonatal lambs. J Med Microbiol 50, 752-758.

Wang, L., Curd, H. \& Reeves, P. R. (1999). Immunization of mice with live oral vaccine based on a Salmonella enterica (sv Typhimurium) aroA strain expressing the Escherichia coli O111 $\mathrm{O}$ antigen. Microb Pathog 27, 55-59.

Wieler, L. H., Vieler, E., Erpestein, C., Schlapp, T., Steinrück, H., Bauerfeind, R., Byomi, A. \& Baljer, G. (1996). Shiga toxinproducing Escherichia coli strains from bovines: association of adhesion with carriage of eae and other genes. Infect Immun 34, 2980-2984.

Woodward, M. J., Gavier-Widen, D., McLaren, I. M., Wray, C., Sozmen, M. \& Pearson, G. R. (1999). Infection of gnotobiotic calves with Escherichia coli O157:H7 strain A84. Vet Rec 144, 466-470.

Wray, C., McLaren, I. M., Randall, L. P. \& Pearson, G. R. (2000). Natural and experimental infection of normal cattle with Escherichia coli O157. Vet Rec 147, 65-68.

Yokomizo, Y., Watanabe, F., Imada, Y., Inumaru, S., Yanaka, T. \& Tsuji, T. (2002). Mucosal immunoadjuvant activity of the low toxic recombinant of Escherichia coli heat-labile enterotoxin produced by Bacillus brevis for the bacterial subunit or component vaccine in pigs and cattle. Vet Immunol Immunopathol 87, 291-300.

Zhao, T., Doyle, M. P., Harmon, B. G., Brown, C. A., Mueller, P. O. \& Parks, A. H. (1998). Reduction of carriage of enterohemorrhagic Escherichia coli $\mathrm{O} 157: \mathrm{H} 7$ in cattle by inoculation with probiotic bacteria. J Clin Microbiol 36, 641-647. 